\title{
Traditions and Innovations in Environmental Education
}

\author{
Zlatka Petkova Vakleva \\ Assistant professor, Faculty of Biology, Plovdiv University "Paisii Hilendarski”, Plovdiv, Bulgaria
}

\begin{abstract}
The article discusses the main events leading to Education FOR Sustainable Development (EDS) under the auspices of UNESCO. It is based on theoretical analysis of literature and documents from international conferences and on the achievements of scientists on Environmental Education (EE) in Bulgaria. The road to education for sustainable development started in ancient times, passed through introduction into schools as the subject nature study and continued as organized activities of global institutions and educators. As the interaction of humanity with nature deepened and became more and more complex, humanity reacted with increased emphasis on Environmental Education (EE). The international educational society at each successive stage of EE undertook competent rethinking of achievements and shortcomings and offered new recommendations for improvement. The history of EE, if critically studied and analyzed, is a rich source of accomplishments, suggesting new ideas for further development. The best of our traditional approaches, interwoven in new theories of learning is more fruitful in educational practice. The study was dedicated to the historical roots and main stages of EE leading to a new model of integrated environmental education of students, pre-service and in-service teacher education and training.
\end{abstract}

Keywords: Education for Sustainable Development, international educational events, advantages and shortcomings, Bulgarian experience, integrated EE model

\section{INTRODUCTION}

Attitude to nature is reflected in the educational heritage $\left(6^{\text {th }}\right.$ century BC). Confucius saw learning as a highly personal and therefore, highly individual process of observation of subject matter followed by reflection. "Study without thought is labor lost; thought without study is dangerous." ${ }^{1}$ Socrates, Plato, and Aristotle considered environment studies important for realistic education. Their philosophy was carried into the Muslim world, from which it was reintroduced into the West to form the foundation of medieval philosophy and the Renaissance ${ }^{2}$. J. A. Comenius, J. J. Rousseau, J. H. Pestalozzi and F. Froebel $\left(18^{\text {th }}-19^{\text {th }}\right.$ centuries $)$ exerted their influence by helping establish the foundations for a concrete environmental education program Nature study. Pestalozzi's motto "Learning by head, hand and heart" is still a key principle in successful schools. Friedrich Fröbel encouraged pupils' self-expression through play, both individually and in group activities. His ideas were creatively developed by John Dewey (after [1]). Nature study societies in collaboration with Ministries of education and teachers initiated outdoor forms of nature conservation education such as to set up school gardens and school forests [2].

German naturalists A. Luben, F. Junge and O. Schmeil introduced ecological approach to Nature study in the late $19^{\text {th }}$ and early $20^{\text {th }}$ centuries by structuring the school curriculum around the communities (ecosystems): marsh, river, etc. They also introduced mandatory training excursions and their experience was disseminated in Europe (after [1]; [3]). Nature conservation education continued as out-of-class and out-of-school activities, such as: planting trees on eroded areas; renewal of water pipes; making parks and gardens as well as wooden "houses" for birds and placing them in trees, preparing winter feeding-troughs for wild animals, etc. After the Second World War nature conservation movement and out-of-school activities covered all schools in Bulgaria. The modern EE movement, which gained significant momentum in the late 1960s and early 1970s, stems from Nature Study and Conservation Education.

In the 60 s of the $20^{\text {th }}$ century a new aim was set in biology curricula: to instill in students love and caring attitude towards nature. Environmental studies were introduced in science curricula and textbooks. Popular science materials on environment protection were issued to help students. New strategies on biology and physics curricula were set in the USA and Great Britain. Ecology chapters and ecological approach were introduced in the biology curriculum. Environmental education was fragmented and mainly in the subject of Biology.

These studies gave us impetus to continue the analysis of historical achievements and look for new ideas of ESD. The search was directed mainly to global educational strategies of world institutions, such as UN, UNESCO, UNEP and IUCN and on their creative implementation in Bulgarian secondary and high schools. 


\section{METHOD}

Theoretical analysis of cited documents and literature and personal experience were applied in studying past and present events in EE. Observation, collecting and evaluation of data were carried out in order to outline the perspectives of EE improvements. Constructive modeling was used in making a summery picture of the main characteristics of an integrated model of EE.

\section{RESULTS AND DISCUSSIONS}

Activities of the International Society on Environmental Education

Global community recognized the need of initiating and continuously developing environmental education at the United Nations' Conference "On the Human Environment" in 1972 (Stockholm) and formulated its decision in recommendation 96 of the final document [4]. This program contains the first full description of environmental education (EE). The day of the Conference opening $-5^{\text {th }}$ of June, was declared as an International day of nature conservation and EE. The EE events followed the organized activities for conservation of the environment (Table 1).

TABLE I LEADING INTERNATIONAL ACTIVITIES

\begin{tabular}{|l|l|}
\hline On conservation of the environment & On environmental education (EE) \\
\hline $\begin{array}{l}\text { 1972: UN Conference on the Human } \\
\text { environment, Stockholm. 1980: World } \\
\text { conservation strategy of living resources for } \\
\text { sustainable development of IUCN, UNEP, WWF }\end{array}$ & $\begin{array}{l}\text { 1975: International Environmental Education Program } \\
\text { (IEEP). 1977: Intergovernmental conference on } \\
\text { environmental education in Tbilisi. The Tbilisi } \\
\text { Declaration: The role, objectives \& characteristics of EE. }\end{array}$ \\
\hline $\begin{array}{l}\text { 1987: Our Common Future - THE World } \\
\text { Commission on Environment and Development } \\
\text { (WCED) }\end{array}$ & $\begin{array}{l}\text { 1987: “Tbilisi + 10" - UNESCO's congress on EE and } \\
\text { training in Moscow. International strategy for action in the } \\
\text { field of EE for 1990's }\end{array}$ \\
\hline $\begin{array}{l}\text { 1992: UN conference on environment and } \\
\text { development in Rio de Janeiro (UNCED); Earth }\end{array}$ & $\begin{array}{l}\text { 1992: Second world congress on education \& } \\
\text { communication on environment \& development in Canada } \\
\text { (1982 First Congress in Canada) }\end{array}$ \\
\hline $\begin{array}{l}\text { 2012: "Rio + 20"; UN conference on sustainable } \\
\text { development - "The future we want". }\end{array}$ & $\begin{array}{l}\text { 2012: "Tbilisi + 35" Environmental education for } \\
\text { sustainable development; ESD - Education for sustainable } \\
\text { development }\end{array}$ \\
\hline
\end{tabular}

The first issue of UNESCO-UNEP environmental education newsletter Connect (1976), was published in January and since then it has been continuously assisting development and implementation of the International Environmental Education Programme (IEEP) ${ }^{6}$. As part of UNESCO, courses for teachers' training, key specialists and inspectors in the field of ecology and environmental protection have been periodically organized ${ }^{7}$.

The world community witnessed several forums on EE: Nevada conference in Carson City (USA, 1970), organized by IUCN that formulated the definition of EE; Ruschlicon conference (Switzerland, 1971), which worked out recommendations for the development of projects and programs on EE; Kroscienko conference of East European countries (Poland, 1972) on the implementation of Rushlicon's recommendations ${ }^{8}$.

In response to the decisions of these conferences Eastern European countries established research teams to develop the principles of nature conservation education (NCE) under the leadership of the Academy of Pedagogical Sciences of the former USSR. The work of Western and Eastern research teams was united by the Commission on Education of IUCN. World politicians, scientists and educators combined their organizational, research, informational and practical competences in preparing a forum - the Belgrade workshop (1975) that created The Belgrade Charter, a global strategy for EE. The $5^{\text {th }}$ parts of the document have not lost their significance so far and sound too up to date. The Belgrade charter initiated "The International Environmental Education Program" (IEEP) of UNESCO [5].

The First intergovernmental conference on environmental education: "Education and the Challenge of Environmental Problems" (1977, Tbilisi, USSR) outlined the major environmental problems and their socio-economic and cultural dimensions, defined the role of education in facing environmental challenges, surveyed current efforts for the development of EE and gave priorities to international cooperation. The 41 recommendations provided guidance for further development of EE.

The Second International UNESCO-UNEP congress on EE and training "Tbilisi +10" (1987, Moscow, former USSR) revised the progress and trends in EE since the Tbilisi conference and stressed the importance of training of teachers and students in general university education. It underlined the necessity of specialized environmental training and outlined the priorities for EE development in the 1990s adopting the International Strategy for action in the field of EE and training for the coming decade [4]. 
The Third Conference "Educating for a Sustainable Future" (1997, Thessaloniki, Greece), five years from Rio de Janeiro, highlighted the critical role of education in achieving sustainability, the important contribution of EE, the elements for further implementation of the program of the Commission for Sustainable Development (CSD) and mobilized action at international, national and local levels. The main guidelines were: education for a sustainable future, reorienting formal education towards sustainability, raising public awareness and understanding, shifting to sustainable lifestyles, investing in education and directing ethics, culture and equity in achieving sustainability [6].

From 1997, with the re-vitalization of "Project 2000+" (1994), the scope of Connect was broadened to cover science and technology education. Each issue of Connect has been helping EE throughout the world although the environmental literacy of humanity has not risen significantly. This is because each generation should learn ecology for itself from the beginning and should acquire environmental literacy on its own.

The Fourth conference on EE (2007, Ahmedabad, India; “Tbilisi + 30") attracted the attention of humanity to the UN "Decade of Education for Sustainable Development" (DESD, 2005-2014) and underlined the key role of education in achieving sustainable development. Its aim was to bridge the gap between EE and ESD. The development of EE since the first conference, thirty years before it, was examined and a global agenda for the DESD was set. Tilbury \& Wortman (2004) outlined five characteristics of ESD: envisioning (imagine a better future), critical thinking and reflection (examine economic, environmental, social \& cultural structures in the context of SD), systemic thinking (acknowledging complexities and looking for links and synergies when trying to find solutions to problems), building partnerships (promoting dialogue and negotiation, learning to work together) and participating in decision-making (empowering people). This conference reinforced Agenda 21 of the Earth Summit (1992).

Agenda 21 was a radical turn in the development of ESD and in humans' relation to nature. Compared with the strategy for protection of living resources (1980, IUCN) it put larger and ecologically sounder purposes. It gave priority to conservation of biological diversity, which was recognized as the basis for maintaining the ecological balance; preservation of habitats of species, including humans; in situe conservation; resource management for sustainable development; pollution control; sustainable agriculture and rural settlements. Each of the adopted 27 principles for SD had its projection in education. Chapter 35 gave priority to science in sustainable community development to expand capacity and human resource development and chapter 36 outlined the framework of the ESD long-term strategy.

The surveys showed that EE was a social need for the solution of the environmental problems and an individual need for adaptation and health preservation. The interest in it significantly increased before and after key international events. EE has been growing steadily for more than 40 years since the first UN conference on the Human environment 9,10,11; its philosophy has been refined; strategies, technologies and techniques have been developed; its implementation in all types of schools and subjects in formal, non-formal and informal education has been expanded. EE has penetrated into the different forms of education of all ages of the population and has become an essential part of life-long education. Nevertheless, the behaviors of people have not become more environmentally responsible, nor more worried about depleting natural resources, nor less consumable and no less destructive to the ecological balance.

Where should we look for the reasons of that situation?

Some of the reasons are: complex structures and functions of the environment; the neglect of ecology in the different models of EE; multiple and permanently increasing needs of the increasing world population; severe, complex, evolutionary established, closely intertwined and continuously changing relationships between humanity and nature; exacerbated global environmental problems; rapidly increasing illiteracy; low state of environmental literacy; rising poverty; expanding domination of capital over culture, justice and equality; emerging new technologies, which widen the gap between them and the technical skills of the workforce; not always environmentally evaluated scientific discoveries and seldom scientifically supported environmental actions, etc.

The environmental situation nowadays is by far not optimistic. The examples are numerous: "The 2010 biodiversity target has not been met at the global level. Despite an increase in conservation efforts, the state of biodiversity continues to decline, according to most indicators, largely because the pressures on biodiversity continue to increase (GBO-3). There have been criticisms of corporate social responsibility from ardent free trade capitalists and antiglobalization activists/environmentalists alike. Energy insecurity combined with other global issues, risks fueling conflicts and repeating past mistakes in history. In addition to all that, the problem of brain drain for many poor countries, losing skilled workers to richer countries, is getting more and more serious."11.

The aim of sustainable development (SD) requires the concern for closely connecting the social challenges to the carrying capacity of natural systems. But so far that is still a dream. The actions in the four domains of economic, ecological, political and cultural sustainability are still being isolated. The UN focused political outcome document offers clear and practical measures as well as hopes for implementing sustainable development (Rio + 20, 2012 "Future We Want", UN Conference). 


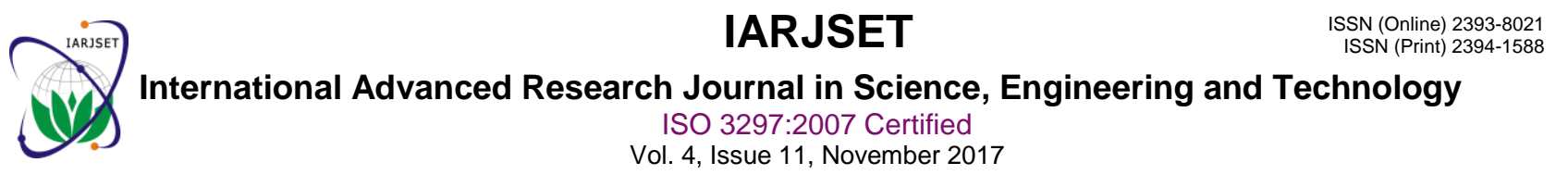

Environmental problems exist in both developed and developing countries, but manifest themselves in different ways. In the former the reason is the uncontrolled growth and in the latter - the population explosion under uncontrolled conditions of economic backwardness. Major cause is the destruction of traditional culture and environmental ethics as well as the development of consumerism and the explosion of ecological and war refugees. The deepening of the environmental and economic crises can lead to short and long term consequences; the short been low standard of life, extinction of many species, health problems, conflicts, terrorism among social groups, fighting for scarce resources; the long-term result of environmental degradation is the inability to sustain human life. Such degradation on a global scale could imply extinction for humanity.

Sustainable Development Strategy (SDS) is seen as salvation from environmental crisis. The further evolution of humanity is possible if hard limits are imposed on all people regardless of where they live, but that requires cooperation of all nations. Environmental imperatives are international and place restrictions on the activities of the parties, corporations and individuals. New conditions for sustainable development must be created including political, economic, social, industrial, technological, administrative, national and international systems. The new environmental situation creates the need to develop appropriate science disciplines and to open any science to the problems of the environment.

First is the need to integrate both environmental and anthropological crises. Damage to the environment (ecological crisis) is a consequence of demographic crisis (exponential growth of humanity), crisis in the economy, technology and social policy, mental and physical health of people. It follows that different aspects of education must submit to a single concept - ESD. SD is not a panacea and does not mean a total waste of prosperity and wealth. The environment is sick, and the people's obligation is to treat it with their responsible behavior in order to provide better conditions for their lives and the lives of future generations. UNESCO's documents characterize ecological crisis as "imperfect understanding of the natural systems and mechanisms which make possible the maintenance of life on earth; disregard of unintentional effects of technology, in particular the various forms of pollution; poor management of soil, forests and water; unbridled consumption of fossil fuel; uncontrolled urbanization; the relegation of the rural population to a marginal position; destruction to the existing background of life; and the crushing of traditional culture.” [7, p. 9].

These changes are not new and the international actions being taken to solve them are not new either. New are their dimensions, broadened and deepened by aggression and terrorism. Their characteristics incorporate ecological, social, economic and cultural aspects, i.e. ecology-anthropogenic dimensions.

New science and social development itself create new values that can be utilized by individuals and incorporated in the culture of society through ESD (Education for Sustainable Development).

Surveys on the students' concerns about nature in Bulgaria also show that their attitudes fluctuate between dominant environmental paradigm (DEP) and the new ecological paradigm (NEP), between anthropocentrism and ecocentrism [8]. The school alone cannot achieve remarkable results if the society does not take serious steps on the road to nature protection on ecological foundations.

The analysis of the presentations at "Rio+20" (2012) confirm the notion that program activities for sustainable development seriously leg behind environmental degradation. Exacerbation of environmental issues threatens to go beyond the control of mankind.

Implementation of programs on sustainable use of different types of resources requires training of qualified staff, improving the competence, facilities and working conditions, motivating and engaging the public. The realization of Agenda 21 objectives is linked closely to the strategic role of ESD in the development of the overall education system. It helps in the integration of objectives, contents and activities at national and international level. Dominant goals throughout Agenda 21 include development of ecological literacy, environmental ethics and business capacities. In relation to the environment, priorities are given to resource conservation, sustainable development, improvement of urban life, protection of biodiversity, the unity of environmental quality and life quality (health and environmental aspects of education) and the development of environmental technologies. Serious steps were undertaken in Bulgaria for up-dating ecology and environmental education [9].

Based on the analysis of achievements and shortcomings of EE our research and teaching practices (2006-2017) were engaged with the following:

- $\quad$ Development and elaboration of an integrated three-stage model of environmental education: first stage - EE of pre-service pedagogy and biology teachers; second stage - EE of in-service life-long qualification of teachers and third stage - EE of secondary education of students from fifth to eleventh grades.

- $\quad$ Construction of new curricula integrating EE in the different courses of pre-service pedagogy and biology: Teaching Practice; Environmental education and upbringing; Methodology of Biology Education; Systematics of 


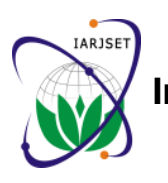

plants; Medical Business Practices; Methodology of training in man, nature and society; Methodology of training mentally retarded students in the subject of man and nature.

- Introduction of new courses, such as Ecological ethics, Bioethics, Biogeography, Man and nature - theoretical module; Man and Nature - teaching practice and Man and Nature - a practical module, accompanied with the development of new programs, lectures, teaching and assessments materials.

- In-service teachers' training courses in the field of ecology and new approaches to interactive EE teaching for science teachers (biology, chemistry and physics).

- Introduction of innovative teaching practices of environmental education of students from fifth to eleventh grades in the subject of biology and health education.

- $\quad$ Professional guidance of pre-service and in-service teachers' research projects in Environmental education.

- $\quad$ Re-thinking and re-writing the teaching and learning materials on the bases of new theories of learning and especially the theory of multiple intelligences [10].

\section{CONCLUSIONS AND FUTURE TRENDS IN ESD}

Despite continued efforts for development the state of the environment continues to deteriorate. Environmental consciousness of humanity continues to lag behind the growing environmental crisis. Therefore it is necessary to achieve domination of sustainability by:

stabilizing the size of the human population; using natural resources rationally; controlling immeasurable greediness of humans; improving quality of the environment; multiplying renewable resources and finding substitutes for nonrefundable; slowing down overproduction, which dissipates resources, creates wastes, presses people to buy unneeded goods or to replace possessed goods with new ones for the sole purpose of increasing the corporations' capital ( e.g. GSM and television apparatuses, etc.).

The humanity should create and develop environment-friendly technologies in energy, transport, agriculture, construction and should ensure sustainable economic growth on sound scientific bases, ignoring political intrigue and speculations.

Future trends in the development of ESD should account for the following needs:

- $\quad$ Each school subject should take adequate part in the development of environmental literacy without redundant repetition of topics and threats. Our integrated three-stage model of EE is a strategy on these grounds.

- The media should stop informational pollution with unscientific statements and unjustified moralizing. Lots of time is dedicated to attribute properties to goods, most of which they do not possess with the sole purpose to stimulate consumption. Without scientific knowledge students cannot distinguish truth from lie, and are forced to accept either everything as truth or everything as lie. Advertising is exaggerated and repeated several times daily becomes truth. It deals with everything, even with pain and grief. The new course on ecological ethics we developed and introduced for pre-service teacher training answers those recommendations.

- A partnership between education, business, science, government and non-governmental organizations and the media is needed to ensure scientifically informed action to solve environmental problems. Ignorant people cannot take right decisions and are easily politically manipulated. People have never needed so much scientific knowledge as nowadays. It is not a surprise therefore that one of the $56 \mathrm{UN}$ recommendations at "Rio + 10 " is a call to promote education about sustainability awareness (recommendation 13). "Knowledge is the greatest tool for human progress but it won't suffice - we also need leadership and determination to work together" (Julia Marton-LeFevre, head of IUCN, speaking at "Rio+10" conference). Our integrated three-stage model of EE was developed and experimentally introduced in order to unite the efforts of school, university and business authorities in up-to-date environmental literacy.

- The recommendations of "Rio+10" are good wishes but humanity needs mechanisms and universal commitment to accomplish them, scientifically prepared and thinking citizens, well trained and skillful specialists in the different aspects of sustainable development. Engaging secondary school students, university students and inservice teachers in continuous, organized and well-equipped with innovative teaching strategies and materials EE, we are striving to improve and widen the environmental culture of Bulgarian population [11].

- $\quad$ Policy makers and educators should continuously rethink and upgrade the past and critically analyze the present through our future goals in order to rightfully direct peoples' motives and efforts. The results from the continuous assessments of the implementation of our three-stage model of integrated EE we use to draw conclusions, to outline benefits and shortcomings and to make duly corrections.

\section{Notes:}

${ }^{1}$ http://www.brainyquote.com/quotes/authors/c/confucius.html

${ }^{2} \mathrm{http}: / /$ philosophy.tamu.edu/ sdaniel/Notes/01class 2. html

${ }^{3}$ http://environmental-education.org/en/who-we-are/99-weec.html - In 1992, the World Congress for Education and

Communication (WEEC) on Environment and Development was held in Toronto, Canada. It was the first major Copyright to IARJSET 
international gathering, after the Rio Conference, to focus on Chapter 36 of Agenda 21, promoting education, public awareness and training. In September 2002, the UN organized the World Summit on Sustainable Development (WSSD) in Johannesburg, South Africa to assess progress made in this direction on a worldwide basis.

${ }^{4}$ http://www.esd-world-conference-2009.org/en/international-advisory-group/members.html In April 2009 in Bonn UNESCO World Conference on Education for Sustainable Development was held. Bonn Declaration inter alia highlighted the importance of the Investment in ESD as an investment in the future, and as possible life-saving measure, especially in post-conflict and least developed countries. Besides, it evaluated the importance of ESD in 21 st century and the progress of DESD (Decade of ESD).

${ }^{5} \mathrm{http}: / /$ www.5weec.uqam.ca/EN/ A successful 5th World Environmental Education Congress!

${ }^{6} \mathrm{http}: / /$ trove.nla.gov.au/work/27594559?selectedversion=NBD44077019;

${ }^{7} \mathrm{http}$ ://www.ibe.unesco.org/en/services/online-materials/publications/educational-innovation-and-information.html Innovations in environmental education.

${ }^{8}$ http://openlibrary.org/authors/OL1784037A/European_Working_Conference_on_Environmental_Conservation_Educa tion_Ru\%CC\%88schlikon_Switzerland_1971 European Working Conference on Environmental Conservation Education, Rüschlikon near Zürich, Switzerland, 15-18 December 1971

${ }^{9} \mathrm{http}: / /$ ec.europa.eu/environment/eussd / Review of the EU Sustainable development strategy

${ }^{10} \mathrm{http}: / /$ sustainabledevelopment.un.org/index.php?menu=1298 Future We Want - Outcome document

${ }^{11}$ http://www.cbd.int/gbo3/?pub=6667\&section=6689 Global Biodiversity Outlook 3

\section{REFERENCES}

[1] G. Paunchev. Historical overview of the methods of Natural History. School review, 1902, v. 7, issue 4, p.262 (In Bulgarian)

[2] Z. Kostova. Conceptualization of Environmental Education. Sofia, Faber, 2003, 254 pages

[3] V. Stanchev, School trips. School review, 1906, v. 11, issue 4, p.277 (In Bulgarian)

[4] ISEE, International strategy for action in the field of environmental education and training for the 1990s. UNESCO-UNEP, Moscow, 1987.

[5] Connect, UNESCO-UNEP Environmental Education Newsletter, Paris, 1976.

[6] UNESCO, Educating for a sustainable future: A transdisciplinary vision for concerted action. International Conference, Thessaloniki, Environment \& Society, Unesco \& the Government of Greece, 1997.

[7] UNESCO, Man and his environment. Paris, 1979.

[8] Z. Kostova, E. Vladimirova, The environmental concern of nine-grade students from a secondary professional school. Bulgarian Journal of Science and Education Policy (BJSEP), 2011, Volume 5, Number 1, p. 178-218.

[9] Z. Kostova, Ecology in Bulgaria. Chemistry: Bulgarian Journal of Science Education. 2015, V. 24, Number 4, pp. $552-628$.

[10] H. Gardner, Multiple intelligences: New horizons in theory and practice. New York, Basic Books, 2006.

[11] Z. Vakleva, Z. Kostova, E. Vladimirova, R. Kaleva, Using interactive case studies to support students' understandings of local environmental factors. BJSEP, 2012, v. 6, No 2: 292-320.

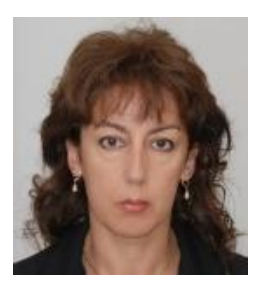

\section{BIOGRAPHY}

Ph.D. Zlatka Vakleva, Assistant professor. She has 23 years' experience as a scientist (researcher and Lecturer) at Plovdiv University Paisii Hilendarski, Biology Faculty, Bulgaria. Author of over 80 publications in Bulgarian and international journals and collections. Author of two monographs, 7 university textbooks, scientific articles, books in the field of education. She is a member of the team of trainers Publishing RAABE - Bulgaria; participates in the preparation of program and educational materials for practical workshops. Trainer for courses for the training of teachers on topical issues of education, which has trained over 250 science teachers from all over Bulgaria. She has membership in professional and scientific organizations and unions: The Union of Scientists in Bulgaria - Plovdiv. Professional areas: Theory and methods of training and education; Interactive technologies and innovations in teaching biology; Interactive technologies and innovations in environmental education; Theory and methods of the didactic experiment. 